\title{
Public Works Projects as Vehicles for Engineering Education and Outreach
}

\section{Ms. Shannon Weiss, David Heil \& Associate, Inc.}

Shannon Weiss is a project coordinator and specializes in the design and implementation of evaluation and market research projects related to DHA's core areas of emphasis in science, engineering, health, and environmental education; and institutional strategic and business planning. Her work serves a range of academic institutions, government agencies, corporations and non-profit enterprises including projects funded by the National Science Foundation and the National Institutes of Health. Prior to joining DHA, Shannon designed and conducted evaluations for Seattle's Woodland Park Zoo, Burke Museum of Natural History and Culture, and the Pacific Science Center. Shannon received a B.A. in Art History from the University of Evansville in Evansville, IN; an M.A. in Museum Studies from the University of Washington in Seattle, WA; and was a member of the initial cohort of the University of Washington's IMLS funded New Directions in Audience Research Program.

\section{Mr. David R. Heil, David Heil \& Associates, Inc.}

David Heil, President of David Heil \& Associates, Inc., (DHA) is well known as an innovative educator, author, and host of the Emmy-Award winning PBS science series, Newton's Apple. Active in promoting public understanding of science for over 30 years, he is a frequent conference and workshop presenter on science, technology, engineering, and mathematics (STEM) education, and his firm provides research and evaluation services for a broad range of government, corporate, non-profit and university clients. Heil is a co-author of Family Engineering: An Activity and Event Planning Guide, and serves as a member-at-large on the Executive Committee of ASEE's K-12 Division.

\section{Dr. Thalia Anagnos, San Jose State University}

Dr. Thalia Anagnos is a professor in the General Engineering Department at San Jose State University where she has taught since 1984. Her research interests are in structural engineering, earthquake loss estimation and risk analysis, engineering education, and informal education. On this project she is helping to develop K-16 materials to complement the exhibits and expand the learning opportunities. 


\title{
Public Works as Vehicles for Engineering Education and Outreach
}

\begin{abstract}
America is built on small and large feats of public works engineering that, although often taken for granted, affect almost every aspect of our daily lives. So how can we celebrate these marvels of utilitarian infrastructure and use them to teach public audiences about the engineering principles, materials, and human innovations that make them possible? This case study will share how one project addressed these questions by leveraging informal learning strategies, multiagency collaborations, and new media technologies to explain the history and engineering of one of the world's most recognizable public work sites: the Golden Gate Bridge.
\end{abstract}

\section{Introduction}

In 2009, the National Science Foundation awarded the Golden Gate Bridge, Highway and Transportation District (GGBHTD) funding to create an outdoor exhibit to interpret the history, engineering, and construction of the Golden Gate Bridge for the site's approximately 10 million annual visitors. ${ }^{1}$ As an iconic example of American public works and prominent tourist destination, the Golden Gate Bridge and this complementary outdoor exhibit demonstrates how public works agencies, in collaboration with local partners, can provide informal engineering education. The specific educational deliverables produced by the project include:

- The design, fabrication, and installation of 17 outdoor exhibit components;

- The participation of undergraduate and masters students in the exhibit's design process as a means of increasing their understanding of engineering principles and their capacity to interpret these concepts for public audiences;

- Increased public access to information related to the Golden Gate Bridge via a smart phone Quick Response (QR) code, which links visitors to online language translations and additional engineering content;

- The creation of an international conference of diverse professionals dedicated to pioneering the use of infrastructure, construction projects, and public works sites as informal, free-choice learning venues; and

- An online professional development course offered to members of the American Public Works Association (APWA).

Through the identification, development, and implementation of these deliverables, the project explored the possibilities, challenges, and benefits of using public works venues to provide sitebased learning. The first half of this paper will examine the relevant role public works and engineering sites can play in supporting science, technology engineering, and math (STEM) education; provide a brief history and explanation of the development and design of the GGBHTD outdoor exhibit; and discuss educational theory that demonstrates the value of freechoice learning. The second half of the paper will present specific findings from the exhibit's preliminary summative evaluation. This section will include observations and visitor feedback; student impacts, and examples of ways the project has supported professionals developing their capacity to create similar visitor experiences.

\section{Untapped Resources: Leveraging Public Works for Engineering Education}

Every day Americans utilize a vast array of modern conveniences made possible by engineering and public works, whether by turning on a light, washing a dish, or driving to work. However, 
citizens rarely have the opportunity to learn about or experience the fundamental science and engineering principles that orchestrate their daily lives. Although public works sites exist in almost every community of the United States, few provide community members the opportunity to learn how STEM principles influence the design or daily operations of these sites.

Historically speaking, the primary domain for STEM education has been formal education institutions (e.i. schools and universities) ${ }^{2}$, but "learning is rapidly becoming the single most important leisure commodity in our society, and the free-choice learning sector has emerged as a flexible, innovative, and efficient device for facilitating the learning that the public craves." 3 The longevity of popular television programs focused on construction projects, infrastructure, technological innovation, and manufacturing, such as Modern Marvels (first aired in 1992 ${ }^{4}$ ) and How Its Made (first aired in $2001^{5}$ ), suggest that there is an established cultural interest in these sites and topics. Despite the opportunities created by public interest in STEM, engineering firms and public works agencies have only recently begun to recognize the underutilized potential of public works to foster community engagement and serve as venues that support public engineering literacy.

When engineers and public works agencies partner with local universities, informal educators, and museum practitioners to leverage their professional expertise to engage communities, numerous benefits are created. In return for investing in simple, cost-effective informational panels, hands-on exhibits, tours, or other informal educational strategies, collaborating partners gain reputations as visible and invested community partners. Providing visitors educational experiences also allows these organizations to memorably showcase how they serve their community. These projects additionally communicate the importance of continued investment in infrastructure development and maintenance while cultivating a STEM literate society. Reciprocally, community members gain an introduction to increasingly relevant STEM principles and a foundational knowledge that prepares them to take an educated and active role in community planning and decision-making.

\section{Golden Gate Bridge: An Outdoor Exhibit}

In order to demonstrate the ability of public works sites to satisfy cultural curiosity through rich visitor experiences, the Golden Gate Bridge, Highway and Transportation District (GGBHTD) partnered with EHDD Architecture, the Consortium of Universities for Research in Earthquake Engineering (CUREE), the Exploratorium of San Francisco, West Wind Laboratory, LightHouse for the Blind, and Princeton University to create an outdoor exhibit at the Golden Gate Bridge. The exhibit explains factors that influenced the Golden Gate Bridge's design and construction through photographs, text panels, hands-on components, and a smart phone Quick Response (QR) code that links visitors to additional web-content and language translations. As of the submission of this paper, the exhibit includes 17 components that share the history of the Golden Gate Bridge's site, construction, and aesthetics; explain the implications of natural forces on engineering design; and demonstrate the fundamental engineering principles that make its design possible. Detailed descriptions of each of the outdoor exhibit component can be found in a companion ASEE article entitled, Public Works for Public Learning: A Case Study. ${ }^{6}$

The outdoor exhibit components are clustered by themes and distributed across a large visitor's area located at the southern end of the Golden Gate Bridge. The largest cluster of exhibit 
components were installed in a pre-World War I artillery installation, called Battery Lancaster, which previously was one of the least visited areas of the site (see Figure 1, circle 4). By incorporating exhibit components into Battery Lancaster, the project revitalized and provided a purpose to this underutilized space and created a dynamic area for contextualized engineering education, free-choice learning, and socialization. Program managers drew visitors to the battery by installing the exhibit's welcome signage (see Figure 1, circle 1) in a walkway between Battery Lancaster and a recently renovated plaza (see Figure 1, circle 6). The installation of a hands-on, kinetic exhibit component and nine historical information panels additionally encouraged visitors to spend more time within the space. Outdoor exhibit components were also installed in four other locations selected for their high foot-traffic; views of the bridge, which provided visual references for specific design features discussed by the components; or a natural element, like wind, that was necessary for creating conditions needed to demonstrate a concept.

Figure 1. Site Map

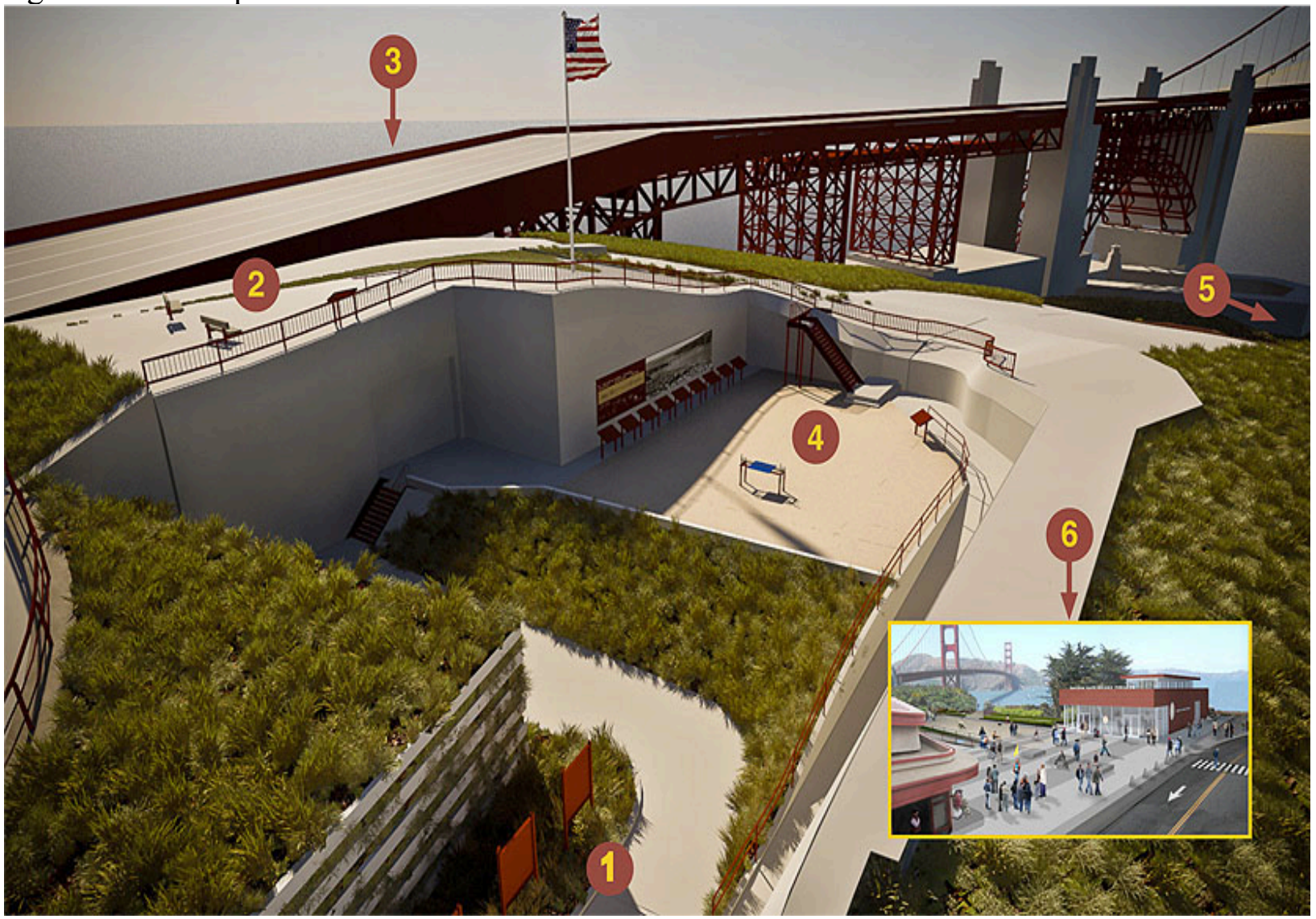

1) Exhibit Welcome Signage; 2) Flag Pole Area (How the Bridge Vibrates Model); 3) Bike Path Under the Bridge (Seismic Retrofit Truss and Seismic Isolation); 4 Battery Lancaster (Tower Height/Cable Tension Model, Nine History Panels, and Mural); 5) Bike Trail (wind pressure components - currently removed); and 6) Visitor Pavilion Area (Lifetiles and Braille Interpretative Model).

\section{Constructing an Educational Experience: The Relevance of Multiple Intelligences, Multiple Entry Points, and Informal, Free-Choice Learning}

Each of the outdoor exhibit components invites visitors to gain a more nuanced understanding of the Golden Gate Bridge. To help visitors achieve a deeper level of engagement with the site, a variety of topics were presented to engage visitors' interests in a variety of formats. Nine text 
panels and a mural explain the history of the site, images and text highlight characteristics that emphasize the aesthetics of its art deco design, and hands-on exhibits allows visitors to physically manipulate objects and personally experience fundamental engineering concepts. A Braille plaque with a three-dimensional replica of a Golden Gate Bridge tower was also developed to provide site interpretation for visually impaired visitors. This variety of topics and formats was intentional and designed to ensure content could be accessible for people at numerous entry points with multiple learning styles.

Figure 2: Observed Exhibit Components

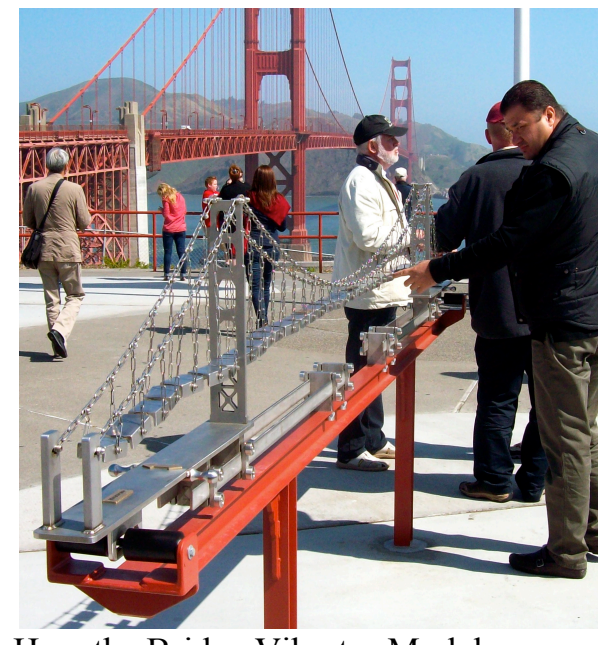

How the Bridge Vibrates Model

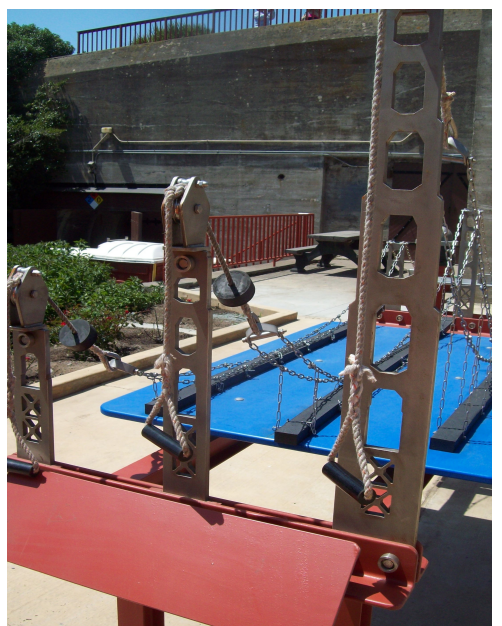

Tower Height/Cable Tension

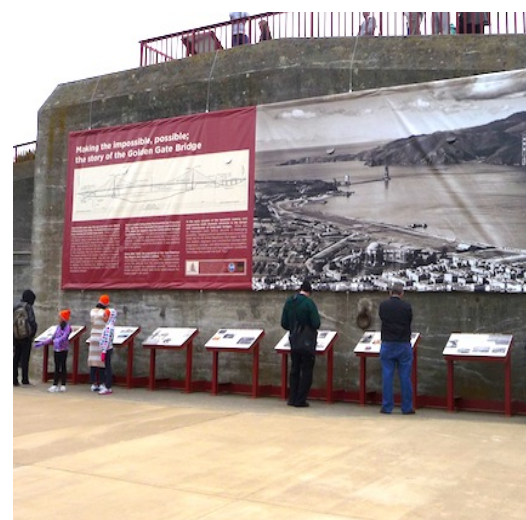

History Panels and Mural

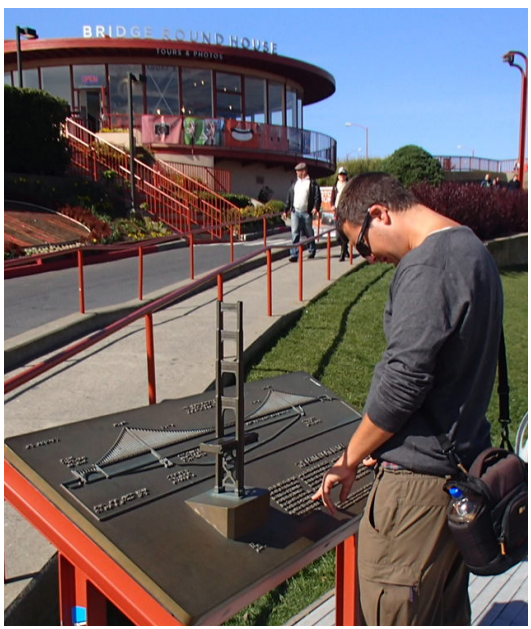

Braille Interpretive Model

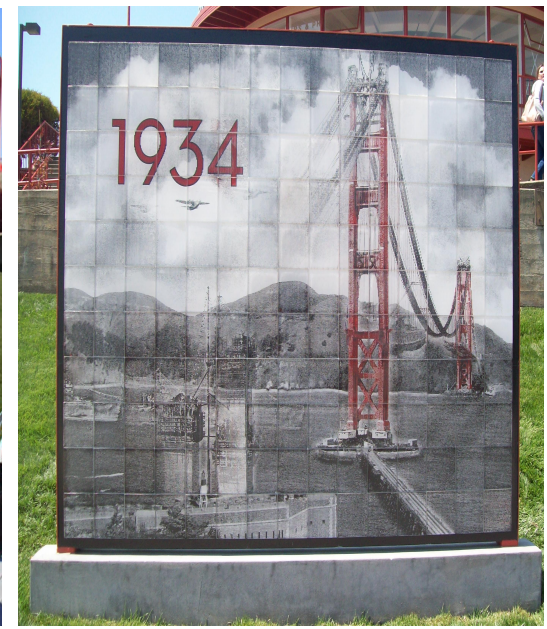

Lifetiles

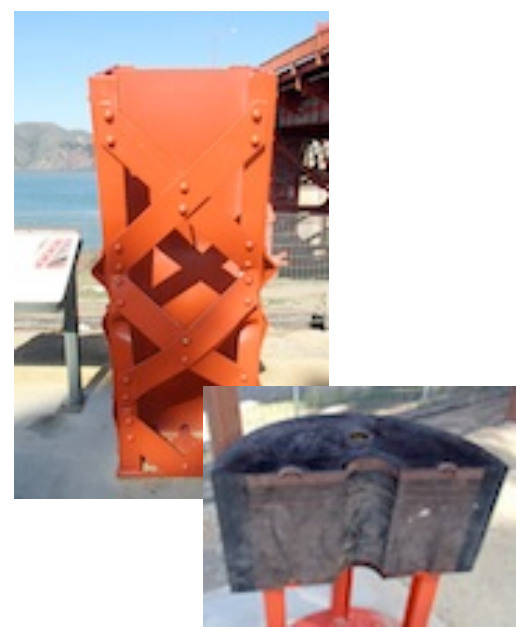

Seismic Retrofit Truss and Isolation

While it was once widely accepted that people learn through a single standard system, cognitive research findings indicate learning is a complex process that no two people pursue in quite the same way. ${ }^{8}$ Howard Gardner, a prominent developmental psychologist, identified seven intelligences that people commonly employ to process knowledge. According to his research, "we are all able to know the world through language, logical-mathematical analysis, spatial representation, musical thinking, the use of body to solve problems or to make things, an understanding of other individuals, and an understanding of ourselves."9 Gardner's theory, known as Multiple Intelligences, acknowledges that people receive, analyze, and organize 
information in a variety of ways and learn most effectively when information is presented in multiple styles. ${ }^{10}$

To achieve this educational dexterity, Gardner recommends that educators present information through five points of entry. By presenting different aspects of a topic through basic principles, narrative stories, quantitative data that invites deductive reasoning, visuals and aesthetic stimuli, and opportunities to directly experience the physicality of a concept, learners have the freedom to engage with the material in whatever learning style is most appropriate for them in that specific moment. ${ }^{11}$ Informal, free-choice learning environments, like the Golden Gate Bridge outdoor exhibit, are well suited for creating the interplay of entry points that support the multiple intelligences.

At its essence, informal learning is any activity that exists outside of the school-based educational system and enables people to pursue knowledge. Examples of informal learning are vast and include, but are by no means limited to, visiting a museum, watching a documentary, building a model car, or reading a book. Like formal learning, informal learning can be the product of an educational experience designed to elicit specific learning objectives. However, informal learning can also be a spontaneous or unconsciously pursued activity, ${ }^{12}$ experienced individually or socially, and can more readily extend across ages, race, culture, language, socioeconomics, abilities, and settings. ${ }^{13}$

While formal education was once deemed the only credible learning environment, the $21^{\text {st }}$ century has seen a shift in the acceptance of informal learning's relevance to personal, professional, and, when used as a complementary experience, even formal educational development. ${ }^{14}$ This acceptance is based on "an increasingly compelling body of research... which shows that choice and control are fundamental constituents of learning." 15 By wanting to learn new information, proactively deciding to participate in an informal learning experience, or sharing the experience socially, an individual is predisposed to becoming an active learner. The freedom of these experiences creates opportunities for the learner to build upon previous knowledge or feel an emotional response to the experience (e.g. anticipation, excitement, or the joy of creating a shared memory), which can make the knowledge gained more memorable and retainable. ${ }^{16}$

\section{More than a Structure: Engaging Communities through Engineering Educations}

When engineering and public works organizations perceive their fabrications to be readymade exhibits within real-world contexts and recognize the importance of informal learning, public works and engineering sites can gain a dynamic social role. As friends and family experience simple, interactive, or aesthetically compelling explanations of history, engineering, and science in venues like the Golden Gate Bridge, these experiences have the potential to become a powerful source of learning. Although the evaluation of the Golden Gate Bridge outdoor exhibit is currently only in its early summative phase, already indications of the project's positive impacts on public audiences have been noted.

In February of 2013, 369 unique observations of visitors interacting with exhibit components and 48 visitor feedback surveys were collected over a three-day period. Protocols were devised to determine the criteria for selecting the observed visitors; visitors interactions with the exhibit 
components were timed; and the frequency of common actions, such as a visitor getting their photo taken with or touching the components, were recorded. When analyzed as a single data set, the visitors' length of stay ranged from three seconds to close to nine minutes. About a third of the visitors $(32 \%)$ stayed at a component for less than 30 seconds, while another third of the visitors (32\%) stayed between 30 seconds and one minute, and the final $36 \%$ stayed one minute to nearly nine minutes. Table 2 presents this same data, but by exhibit component and includes the quantity of observations, their cumulative length, and visitors' average length of stay. ${ }^{17}$

Table 2. Visitor Observations

\begin{tabular}{|c|c|c|c|}
\hline Exhibit Component & $\begin{array}{c}\text { Number of } \\
\text { Observations }\end{array}$ & $\begin{array}{c}\text { Cumulated Length of } \\
\text { Observations }\end{array}$ & $\begin{array}{c}\text { Average } \\
\text { Length of Stay }\end{array}$ \\
\hline How the Bridge Vibrates Model & 109 & $3 \mathrm{hrs} 05 \mathrm{~min}$ & $44 \mathrm{sec}$ \\
\hline Tower Height/ Cable Tension Model & 57 & $2 \mathrm{hrs} 19 \mathrm{~min}$ & $1 \mathrm{~min} 07 \mathrm{sec}$ \\
\hline History Panels and Adjacent Mural & 34 & $2 \mathrm{hrs} 05 \mathrm{~min}$ & $2 \min 30 \mathrm{sec}$ \\
\hline Braille Interpretive Model & 29 & $1 \mathrm{hr} 3 \mathrm{~min}$ & $31 \mathrm{sec}$ \\
\hline Lifetiles & 84 & $2 \mathrm{hrs} 19 \mathrm{~min}$ & $48 \mathrm{sec}$ \\
\hline Seismic Retrofit Truss and Seismic Isolation & 56 & $2 \mathrm{hrs} 05 \mathrm{~min}$ & $1 \mathrm{~min} 14 \mathrm{sec}$ \\
\hline Total: & 369 & 12 hrs $56 \mathrm{~min}$ & $6 \mathrm{~min} 54 \mathrm{sec}$ \\
\hline
\end{tabular}

Visitors viewed the History Panels and Adjacent Mural longer than any other components, and the evaluator observed numerous visitors reading each of the nine panels sequentially. Two hands-on, kinetic components, the How the Bridge Vibrates Model and Tower Height/Cable Tension Model (both kinetic components), demonstrated greater disparity in lengths of stay. While both hands-on components attracted significant initial attention, the How the Bridge Vibrates model presented a more complex engineering concept and its signage was placed farther away from the component in comparison to the Tower Height/Cable Tension Model. These two factors are likely to be the cause of the reduced length of stay, but further evaluation will be conducted to be certain. The amount of time visitors' spent at the two seismic components was also interesting because they were located in an area with little visitor foot traffic. However, people who did find the components were able to touch physical examples of a truss and seismic isolator and directly see where the components were positioned within the actual Golden Gate Bridge structure. This resulted in numerous interactions between visitors (34\% of the component's visitors; see Table 3 ) and more references to the actual bridge than any other component ( $23 \%$ of the component's visitors; see Table 3$).^{18}$

As a component designed to present a quick visual interpretation of how the Golden Gate Bridge appeared during each year of its construction, the Lifetiles also generated a significant amount of interactions between visitors ( $65 \%$ of the component's visitors; see Table 3 ). People were fascinated by how the visual appearance of each tile changed as they walked by and would stop to investigate. Finally, visitors on average only stayed at the Braille Interpretive Model for 30 seconds. This particular component, though, was designed for a select audience, and yet it still prompted many visitors to stop, touch, and even discuss the Braille, which created an additional layer of interaction and learning. ${ }^{19}$

Although the overall average length of stay per component was brief, the evaluator still observed notable exhibit and social interactions. The percentage of visitors that actively engaged with each component via six targeted interactions can be seen in Table 3, and any interaction that occurred 
in at least half of a component's observations have been bolded. Due to the various design formats incorporated into the exhibit, some components were not created to elicit certain interactions, which is indicated by " $N / A$ " within the table. ${ }^{20}$

Table 3. Visitor Observations by Exhibit Component and Interaction

\begin{tabular}{|c|c|c|c|c|c|c|}
\hline (1) & $\begin{array}{l}\text { Touches } \\
\text { component }\end{array}$ & $\begin{array}{l}\text { References } \\
\text { real Golden } \\
\text { Gate Bridge }\end{array}$ & $\begin{array}{l}\text { Uses } \\
\text { component } \\
\text { to interact } \\
\text { with others }\end{array}$ & $\begin{array}{l}\text { Takes a } \\
\text { photo of the } \\
\text { component }\end{array}$ & $\begin{array}{l}\text { Gets their } \\
\text { photo taken } \\
\text { with the } \\
\text { component }\end{array}$ & $\begin{array}{l}\text { Looks at text } \\
\text { panel }\end{array}$ \\
\hline $\begin{array}{l}\text { How the Bridge } \\
\text { Vibrates Model }\end{array}$ & $72 \%$ & $6 \%$ & $31 \%$ & $30 \%$ & $17 \%$ & $\begin{array}{l}9 \% \text { (before }^{*} \\
17 \% \text { (after) } *\end{array}$ \\
\hline $\begin{array}{l}\text { Tower } \\
\text { Height/Cable } \\
\text { Tension Model }\end{array}$ & $91 \%$ & $5 \%$ & $60 \%$ & $11 \%$ & $11 \%$ & $\begin{array}{l}35 \% \text { (before) }{ }^{*} \\
35 \% \text { (after) } *\end{array}$ \\
\hline $\begin{array}{l}\text { History Panels } \\
\text { and Adjacent } \\
\text { Mural }\end{array}$ & $\mathrm{N} / \mathrm{A}$ & $\mathrm{N} / \mathrm{A}$ & $41 \%$ & $15 \%$ & $\mathrm{~N} / \mathrm{A}$ & $82 \%$ \\
\hline $\begin{array}{l}\text { Braille } \\
\text { Interpretive } \\
\text { Model }\end{array}$ & $56 \%$ & N/A & $13 \%$ & $13 \%$ & $3 \%$ & $40 \%$ \\
\hline Lifetiles & $13 \%$ & N/A & $65 \%$ & $25 \%$ & $11 \%$ & N/A \\
\hline $\begin{array}{l}\text { Seismic Retrofit } \\
\text { Truss and } \\
\text { Seismic Isolation }\end{array}$ & $60 \%$ & $23 \%$ & $34 \%$ & $14 \%$ & $9 \%$ & $\begin{array}{c}52 \% \text { (before)* } \\
38 \% \text { (after)* }\end{array}$ \\
\hline
\end{tabular}

* Indicates the percent of visitors who looked at provided text before or after they touched a component

In addition to seeing the Golden Gate Bridge first hand, the creation of the outdoor exhibits provides visitors an enhanced experience through tactile, educational, and social interactions. At least $50 \%$ of observed visitors at each exhibit component engaged in one of the targeted interactions, and a third of the observed visitors additionally used the exhibit components (except the Braille Interpretive Model) to interact with other visitors.

While the depth of the learning prompted by the individual components and interactions has yet to be determined, the 48 self-reported visitor surveys suggest that the interactions do, in fact, enrich the visitor experience. The small sample of respondents, which will continue to grow and culturally diversify as data collection continues throughout 2013, used an iPad to complete the survey. These respondents shared their basic demographics, identified how regularly they visit the site, and rated the impact the outdoor exhibit had on their understanding and overall experience. $^{21}$

The respondents' feedback was highly positive, and for each of the five provided statements (see Figure 5), more than $85 \%$ of the respondents selected either "Agree" or "Strongly Agree," and at least 50\% of the respondents selected "Strongly Agree," for each statement. While these responses are self-reported and do not reveal exactly what the visitors learned, they do indicate visitors believed they gained knowledge in a fun and engaging manner. Moreover, when the survey asked the respondents to rate their agreement with the statement, "I would be interested in 
seeing hands-on exhibits and/or panels at a public works site near where I live," nearly threefourths of the respondents selected either "Agree" (30\%) or "Strongly Agree" (43\%). ${ }^{22}$

Figure 5: Experiential Value of the Exhibit

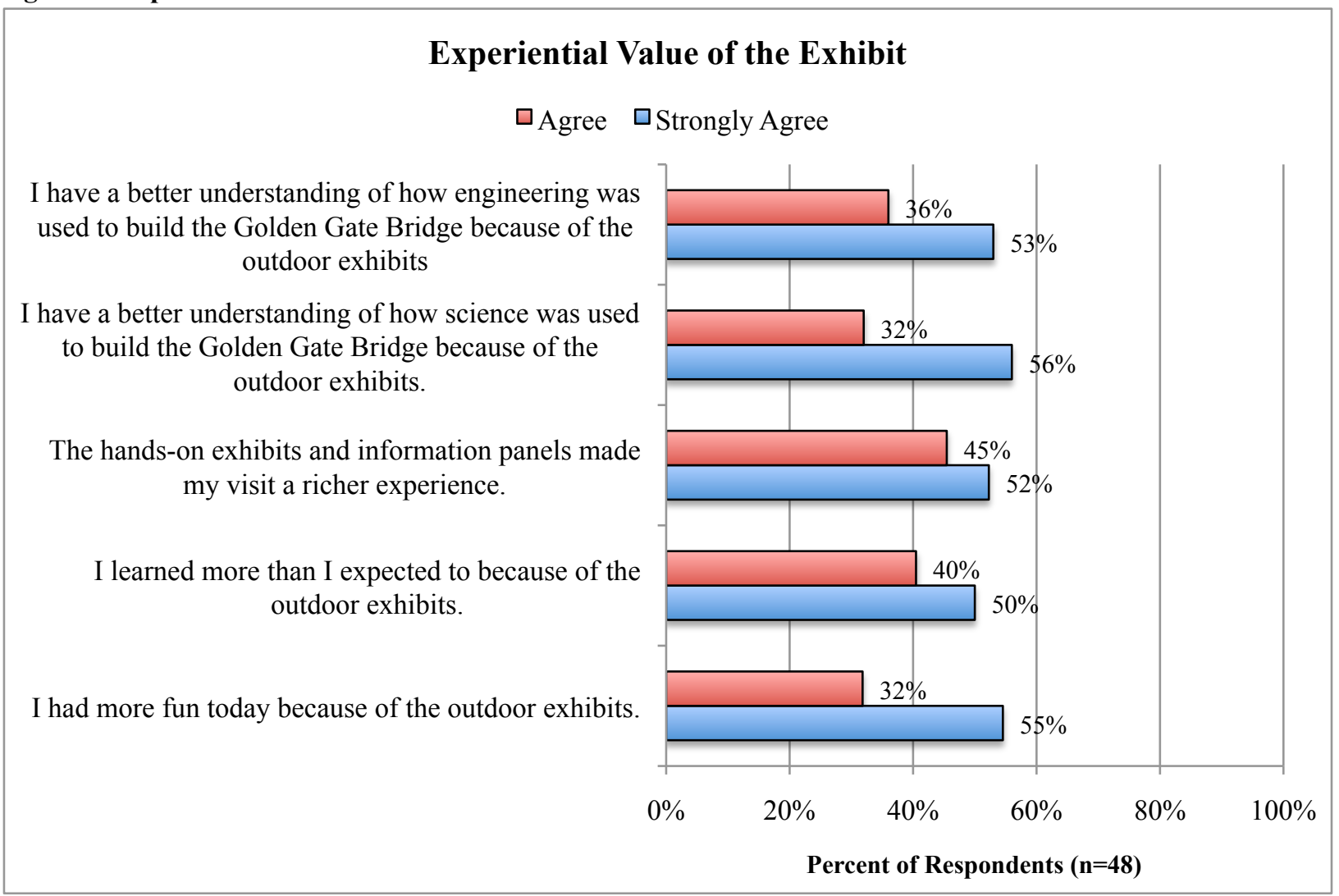

The 48 survey respondents were also asked if they had used a smart phone to access language translations or additional web-based content, but none of the respondents had utilized this resource. While the exact cause for this trend has yet to be determined, there are several possible explanations for this response. For example, the QR code was only included on the exhibit's welcome signage during the three-day observation period, which could have limited the number of visitors who recognized this service given the multiple exhibit locations. The survey was additionally administered to only a small sample of English speaking visitors who did not require language translations. As data collection continues through 2013, the sample will expand to include international visitors and become more representative of potential QR code users. Meanwhile, asking tour guides to notify international visitors of the QR code's presence or incorporating the QR code onto more exhibit components could increase visitors' awareness and use of this resource. ${ }^{23}$

\section{Preparing for the Future: Student Impacts}

The GGBHTD outdoor exhibit project proposes that public outreach and education activities can transform engineering and public works sites into valuable venues of learning. Moreover, the creation of these exhibits, tours, architectural embellishments that highlight structural design elements, and other community engagement strategies can serve as a memorable pedagogical tools. Recognizing the educational opportunities of the outdoor exhibit, project managers invited 
Princeton University students to contribute to the development of exhibit components that illustrate aspects of the bridges' engineering design.

Dr. Maria Garlock from Princeton University's Department of Civil and Environmental Engineering teaches a Studio for Engineers course every two years. The theme of the course changes each year, and when asked to participate as one of the grant's project partners, she incorporated the Golden Gate Bridge into her next course. Instead of learning engineering principles in a traditional classroom setting, Garlock provided her students the opportunity to explore and experience engineering principles by engaging with real structural and interpretive elements. The Studio for Engineers was structured as an informal learning environment, which allowed the students to not only conduct research, calculations, and computer modeling, but also synthesize their complex and nuanced research conclusions into three-dimensional expressions of actual concepts. Moreover, their final results had to be of professional quality for public exhibition and appropriately designed for public understanding and engagement. ${ }^{24}$

While 15 Princeton students participated in the project to some degree, 10 students were heavily involved in exhibit research and design. The Princeton students received their initial data from the GGBHTD, but continued their research within the Princeton based Studio for Engineers. The primary task assigned to the Princeton team was the development of a 1:80 ${ }^{\text {th }}$ scale model of the Golden Gate Bridge. This $90 \mathrm{ft}$ exhibit component with $10 \mathrm{ft}$ tall bridge towers is the centerpiece of the exhibit, and will be installed after a cut is made into the battery wall to provide the required space in the area (see Figure 1, circle 4). ${ }^{25}$

In 2008, Sylvester Black and Will Plunkett began working on the $1: 80^{\text {th }}$ scale model. Over the course of their work, Black and Plunkett had to determine how the model's suspenders would connect to the model's deck, account for wind and seismic variables, produce material studies to address the site's corrosive environment, and plan for the impact of visitors. As illustrated in Figure 6, a "teenager load test" was conducted to ensure the bridge was strong enough to carry the weight of a person, since, as Black shared, "if you build it, they will climb it." 26 Sophisticated Auto-CAD drawings were also created by Black and fellow Princeton student, Maryanne Wachter, which gave both students an opportunity to learn how to communicate their knowledge and ideas regarding a 3-Dimensional object through two dimensional drawings. As Garlock shared, these students were "not just learning Auto-CAD. The drawings have to speak about what you [as an engineer] mean."27

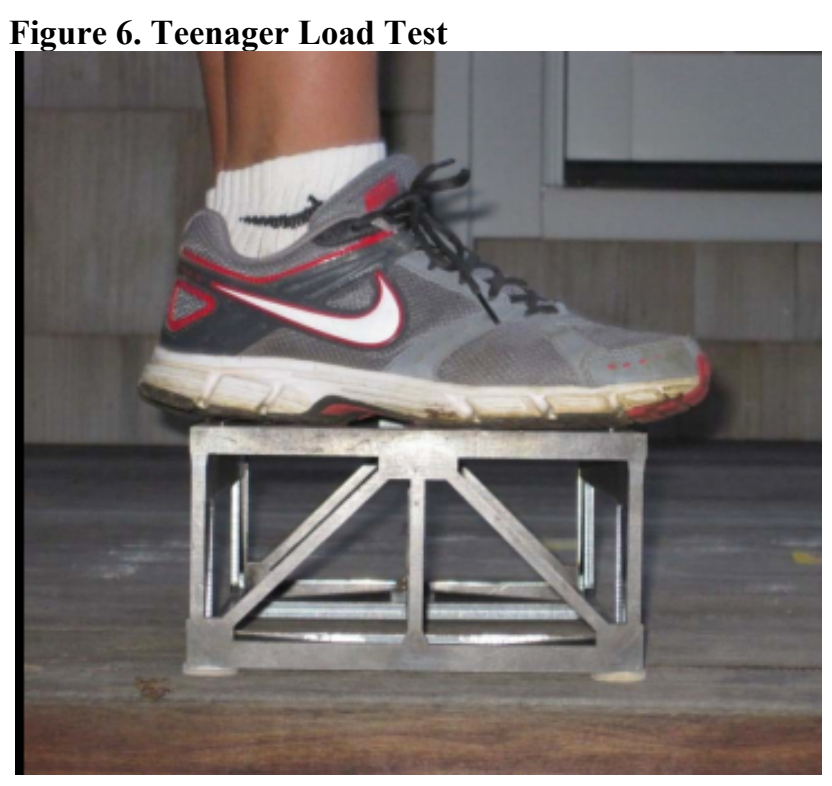


While the $1: 80^{\text {th }}$ scale model was the most prestigious of the Princeton developed exhibit components, students were also responsible for independently and collaboratively producing three other exhibit components. Liz Deir produced torsion and wind dynamics models (see Figure 7), which are located on the site's bike trail (see Figure 1, circle 5). Two models of the bridge's deck were cantilevered off of an exhibit panel. The first model had trusses only along the bridge's top deck, while the second model included lower trusses. Handles were placed on one end of each model, which allows visitors to twist the decks and feel the difference in stability. Gavin Daly produced another component to demonstrate how winds can dynamically affect structures. The research associated with this component was complex and resulted in his Master's thesis. And finally, Tara Wigand produced a galvanic corrosion study used to determine the appropriate material for the Braille Interpretive Model. Additional students produced drawings, contributed research, and supported model construction. Academically, the students' efforts corresponded to a Masters thesis, two senior theses, a senior thesis initiated by an independent study project, and five independent study projects. ${ }^{29}$

The project model of engaging university students in exhibit design and fabrication created by GGBHTD and Princeton University can easily be replicated at higher learning institutions throughout the country. Based on the needs and resources of each set of collaborative local partners, the scale and length of these interpretive projects may vary greatly. Clearly, though, students could be similarly tasked to provide interpretation for local public works, or to provide interpretation of on-campus construction projects for their fellow students. By consulting with local public works agencies, engineering and architectural firms, and construction sites, students can gain an opportunity to engage with real data and structures, learn to professionally interact with other project partners, and begin to learn how to convey their knowledge of engineering principles to interested parties with limited engineering backgrounds.

Public works interpretive collaborations could also be more interdisciplinary. Temporary exhibits for local schools could be designed as a means of creating valuable resources to support the next generation science standard's inclusion of engineering. Project teams of engineering students, education students, and fine art and music students could be organized and tasked with the creation of a specific design project that explains one or more engineering concepts. During the process of developing their exhibits, students from departments that rarely overlap would a. Model without lower truss

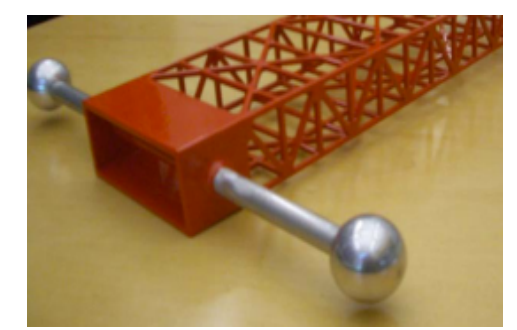

b. Model with lower truss

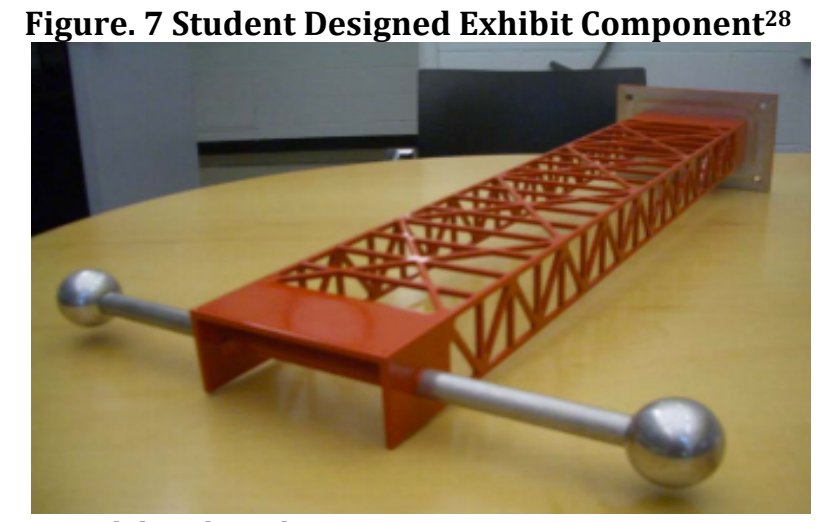

\section{.}

, 
have the opportunity to collaborate in a manner that allows each to demonstrate the value of their professional skill sets and perspectives.

\section{Pioneers: Public Works for Public Learning Conference}

In addition to actively engaging public and university student audiences, the GGBHTD project wanted to disseminate lessons learned during the outdoor exhibit's development with other professional audiences. To accomplish this deliverable, the project mangers organized a small international conference, which gathered pioneers of informal, site-based engineering education from around the world. The two-day Public Works for Public Learning conference was held at the end of June 2012, in San Francisco, CA. GGBHTD invited 25 representatives from sites of various sizes and nationalities to speak at the conference and share insights into how they have developed public education and outreach opportunities that convey the unique history, engineering, and services of their sites. The conference began with GGBHTD project partners presenting the experiences, challenges, and rewards of participating in this particular collaborative endeavor. Through these speakers and a tour of the actual outdoor exhibit, conference attendees were introduced to how the collaboration was developed, the goals and deliverables of the project, and how the outdoor exhibits were researched and fabricated.

Representatives of the Eiffel Tour, the Sydney Harbour Bridge Climb experience, the Panama Canal, and the Hoover Dam provided additional examples of how other large-scale public works sites can engage visitors through public education and outreach. ${ }^{30}$ While these programs and projects represented a diverse set of sites, services, funding sources, and content delivery mechanisms (e.g. exhibits, tours, programs, etc.), each site shared the common goal of encouraging visitors to personally explore, experience, and learn. John Bowe, Project Director at the Sydney Harbor Bridge Climb, succinctly expressed the overarching lesson of these presentations by explaining that successful outreach initiatives consistently provide value to visitors' experiences. These outreach activities enhance the story of a site in a way that invites people to feel inspired by engineering achievement. ${ }^{31}$ The internationally recognized, large-scale projects were then balanced by examples of smaller public works sites that provide public education and outreach. Through these presentations, the observation that, "there are big and small projects, but there are no easy projects," became evident. ${ }^{32}$ This segment of the conference included a panel of APWA sites; a representative from WaterWorks, a community gathering space established at a restored hydroelectric plant that provides educational site interpretation; and the Bay Model Visitor Center. ${ }^{33}$ Although the scale of these projects were smaller, the creativity, vision, and utilization of local partnerships mirrored their larger counterparts.

In order to support conference attendees' operational understanding of public outreach and education projects - both large and small - advice from informal educational professionals was also incorporated into the conference's proceedings. These presentations ranged from the iterative process of exhibit design, the benefits provided by audience feedback and project evaluation, examples of potential funding sources, an introduction to opportunities provided by local museum collaborations, and strategies to increase site accessibility and interpretation for audiences with physical, visual, or auditory impairments.

The Public Works for Public Learning conference's holistic representation of projects, challenges, and developmental considerations produced a highly effective event as demonstrated 
by participant feedback. Two weeks after the conference, presenters and attendees were asked to complete an online post-conference survey. Thirty-five participants, representing an assortment of professional backgrounds (see Figure 8), responded. $^{34}$

Post-conference data provided insights into various aspects of the conference. On a five point Likert-scale, respondents rated the value of the following five elements of the conference:

1.) Professional Diversity of Presenters;

2.) Variety of Session Topics;

3.) Variety of Project Examples;

4.) Range of Project Sizes/Scale; and

5.) Experiencing the Golden Gate Bridge Outdoor Exhibit.
Figure 8. Conference Participants by Professional Fields

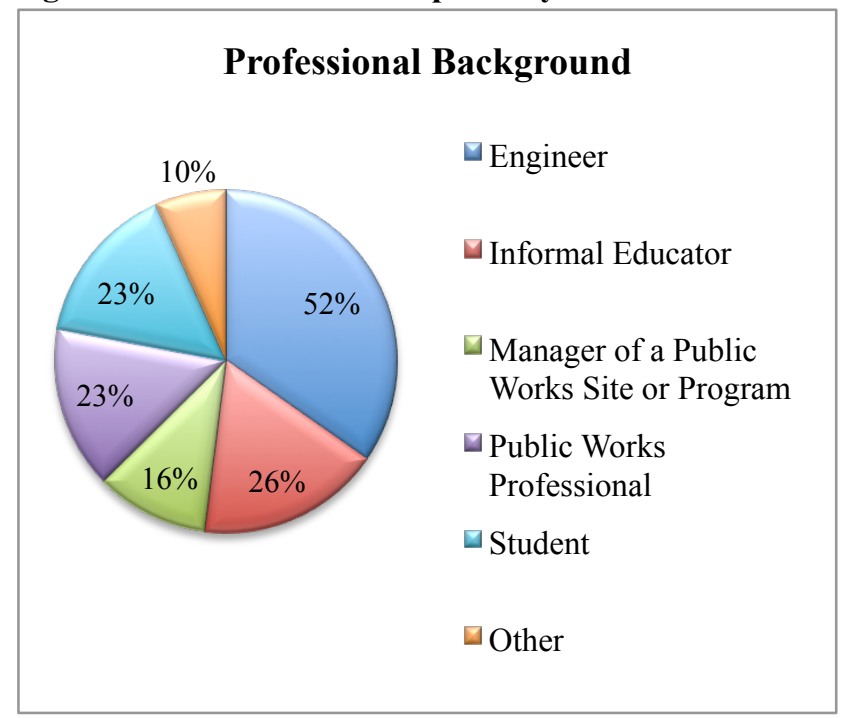

Respondents rated the elements by selecting one answer from five rank-ordered responses, and over $85 \%$ of respondents selected either "Valuable" or "Extremely Valuable" when rating each of the five elements. This strong response indicates respondents were generally satisfied with the conference, especially the "Professional Diversity of Presenters" (65\% selected, "Extremely Valuable"), the "Range of Project Sizes/Scale" (59\% responded with, "Extremely Valuable"), and the "Variety of Project Examples" (56\% selected, "Extremely Valuable"). ${ }^{35}$

Figure 9. Perceived Value of the Conference

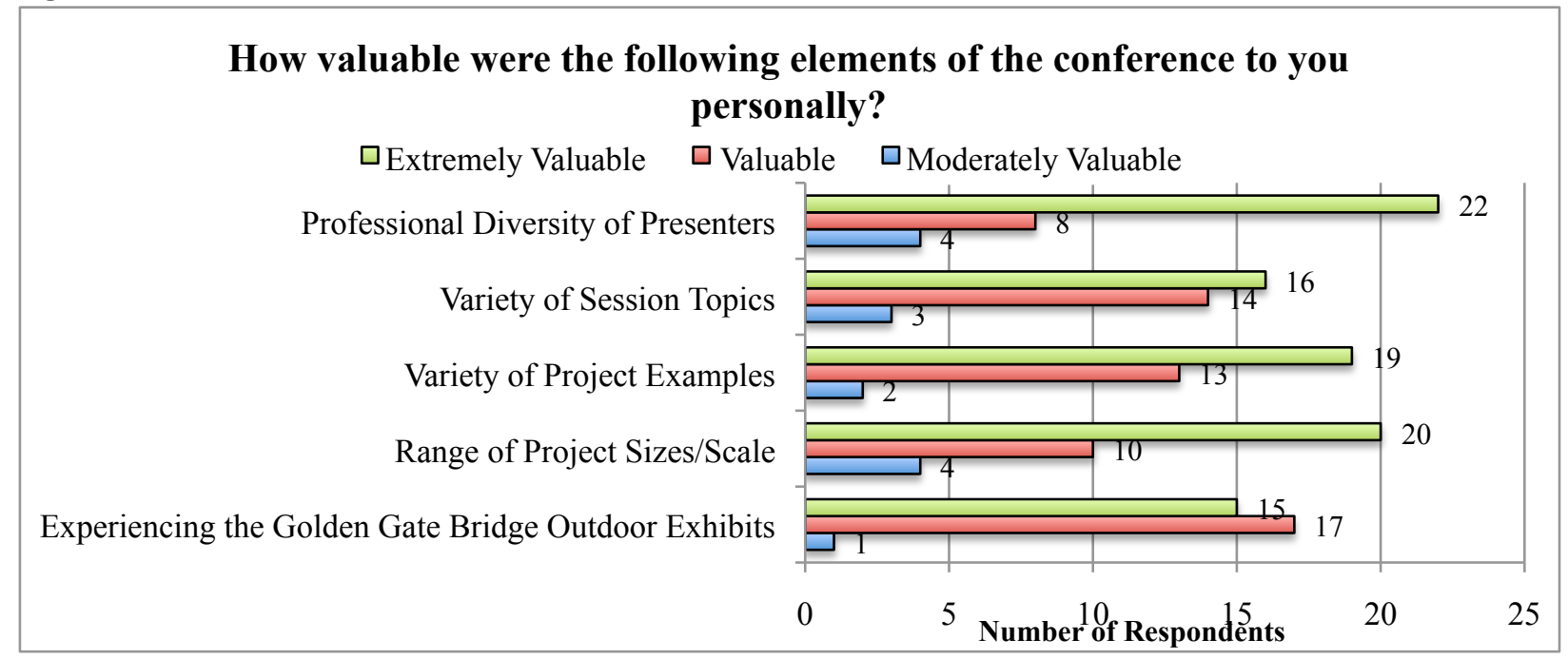


Each respondent additionally shared the three most important things they learned during the conference. While many respondents listed presentation-specific information they found personally useful or interesting, five key themes emerged from the collective responses:

1.) Networking with highly experience professional from numerous fields interested in a similar topic;

2.) Exposure to diverse projects and outreach activities;

3.) Ideas and relationships that could lead to future projects;

4.) Justifications for expenditures; and

5.) Realization that every project has a story to tell. ${ }^{36}$

Finally, the post-conference survey asked participants to provide a written response to the openended question, "As a result of the Public Works for Public Learning conference, what opportunities/outcomes would you most like to see developed to advance this field of work?" Participants' answers were diverse and reflected the conference's broad professional audience. The most common response though was a request for increased dissemination via related project presentations at other professional conferences for engineering, public works, and informal science education practitioners. In particular, these comments voiced a need for the continued development of interdisciplinary collaborations and for more information regarding potential funding sources that support public education programs and projects at both large- and smallscale sites. ${ }^{37}$

\section{Creating a Foundation: APWA Professional Development}

Since one of the primary purposes of the Golden Gate Bridge outdoor exhibit was the development of a collaborative model to investigate the capacity of public works and construction sites to serve as venues for informal education, the APWA's membership was identified as a key professional audience early within the project's development. A survey was administered to APWA members during a two-week period in May 2012, to 1) assess their interest in attending the Public Works for Public Learning conference; 2) assess interest in future professional development opportunities; and 3) to identify their current outreach practices. The survey was emailed to the entire membership twice during the collection period and prompted 659 APWA members to respond.

While the majority of the APWA respondents were not able to attend the conference, the APWA respondents still provided useful insights regarding current APWA public education and outreach practices. For example, only half Table 4. APWA Familiarity with Public Outreach Terminology of the respondents had "Frequently" heard the terms "Public Outreach" and "Public Education" used to describe the process of reaching out to public audience, while even fewer APWA members were familiar with three additional terms commonly used by Informal Science Educators to describe this type of work. ${ }^{38}$

\begin{tabular}{|l|c|c|c|}
\hline & $\underline{\text { Often }}$ & $\underline{\text { Frequently }}$ & $\underline{\text { Total }}$ \\
\hline Public Outreach & $20 \%$ & $54 \%$ & $\mathbf{7 4 \%}$ \\
\hline Public Education & $25 \%$ & $48 \%$ & $\mathbf{7 3 \%}$ \\
\hline Educational Outreach & $20 \%$ & $28 \%$ & $\mathbf{4 8 \%}$ \\
\hline Public Interpretation & $11 \%$ & $6 \%$ & $\mathbf{1 7 \%}$ \\
\hline Informal Science Education & $3 \%$ & $4 \%$ & $\mathbf{7 \%}$ \\
\hline
\end{tabular}


Fortunately, APWA representatives serving on the project's advisory board had anticipated this response, and a follow-up question was included in the survey. This question asked the APWA members to select examples of education and outreach activities previously used by their organizations to interact with public audiences. A list of possible answers was initially developed by the evaluators and then refined by APWA advisors. The resulting 17 possible education and outreach strategies listed in the survey were

- Websites

- Interpretive Exhibits and Displays

- Public Lectures

- Field Trips to Public Works Sites

- Television (e.g., Local News Story, Cable, etc.)

- Radio (e.g., Local News, Advertising)

- Collaboration with Local Museum and/or Science Centers

- Public Newsletter

- Internships at Public Works sitfor Students
- Guided Tours of a Public Works Site

- After School Programs

- Outreach Program Delivered in a School or Community

- National Public Works Week Open House

- Project Specific Open House

- Public Hearings

- Other

- Have Not Engaged in These Types of Activities

Of the 17 potential strategies, only four were selected by over $50 \%$ of the APWA respondents (see Figure 10). These frequently selected responses were "Websites" (86\% of respondents), "Public Hearings (70\% of respondents), "Public Newsletters" (65\% of respondents) and "Interpretive Exhibits and Displays" (54\%). ${ }^{39}$

Figure 10. Current APWA Public Education and Outreach Strategies Used By APWA Members

\section{Primary Public Education and Outreach Efforts Currently Used by APWA}

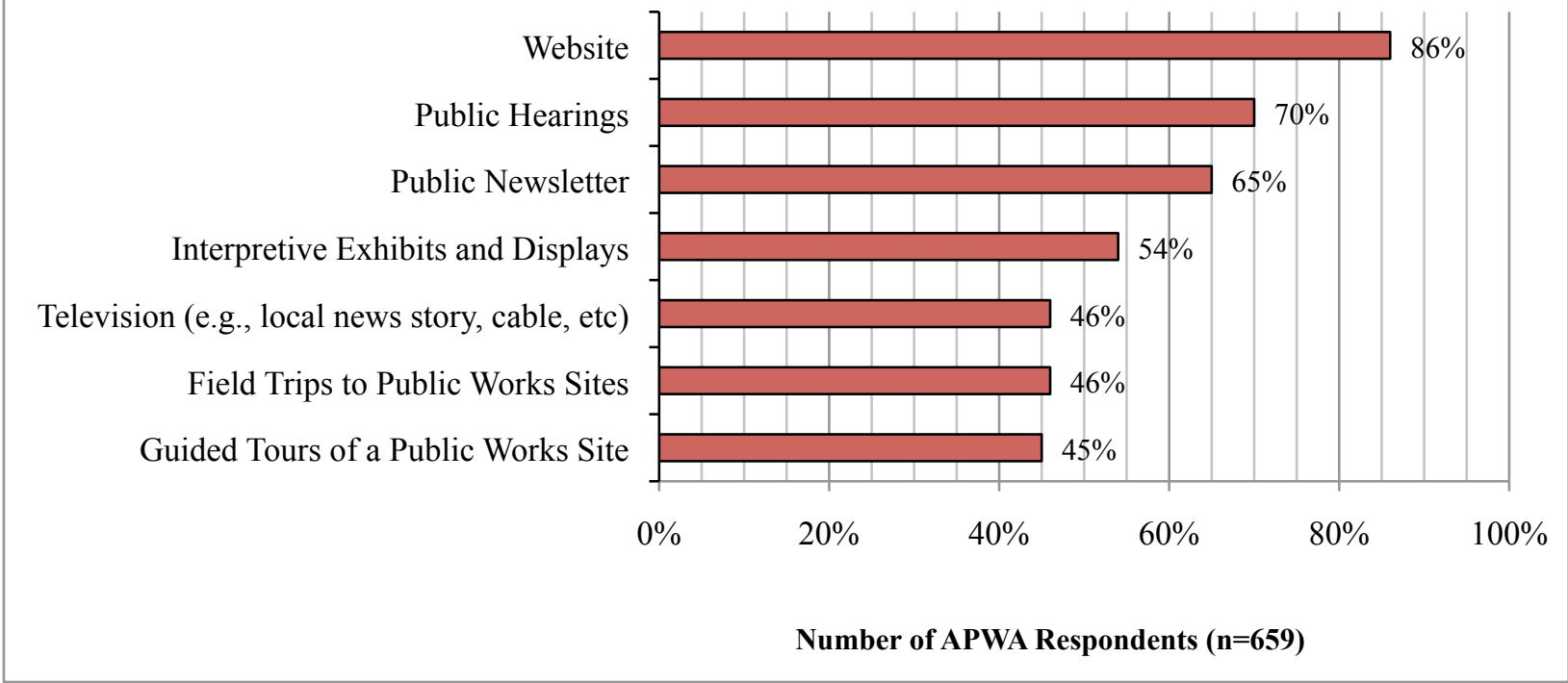


While the previous two survey questions were used to gain insight into APWA members' familiarity with public education and outreach and its related delivery mechanisms, the survey also gathered information regarding whether or not APWA agencies provided public education and outreach specifically focused on the science and engineering involved in their work. As demonstrated by Figure 11, nearly three-fourths (70\%) of the 659 respondents selected "Rarely" (31\%) or "Sometimes" (39\%) when answering the question, "Do public works agencies and/or contractors in your community currently provide education and outreach activities that share the science and engineering involved in their work?" Only 14\% of the respondents reported that their agencies either "Always" (2\%) or "Usually" (12\%) provided public engineering or science specific interpretation. ${ }^{40}$ So, while many agencies aspire to some form of public education and outreach, very few are highlighting the science and engineering aspects of their work in their outreach activities.

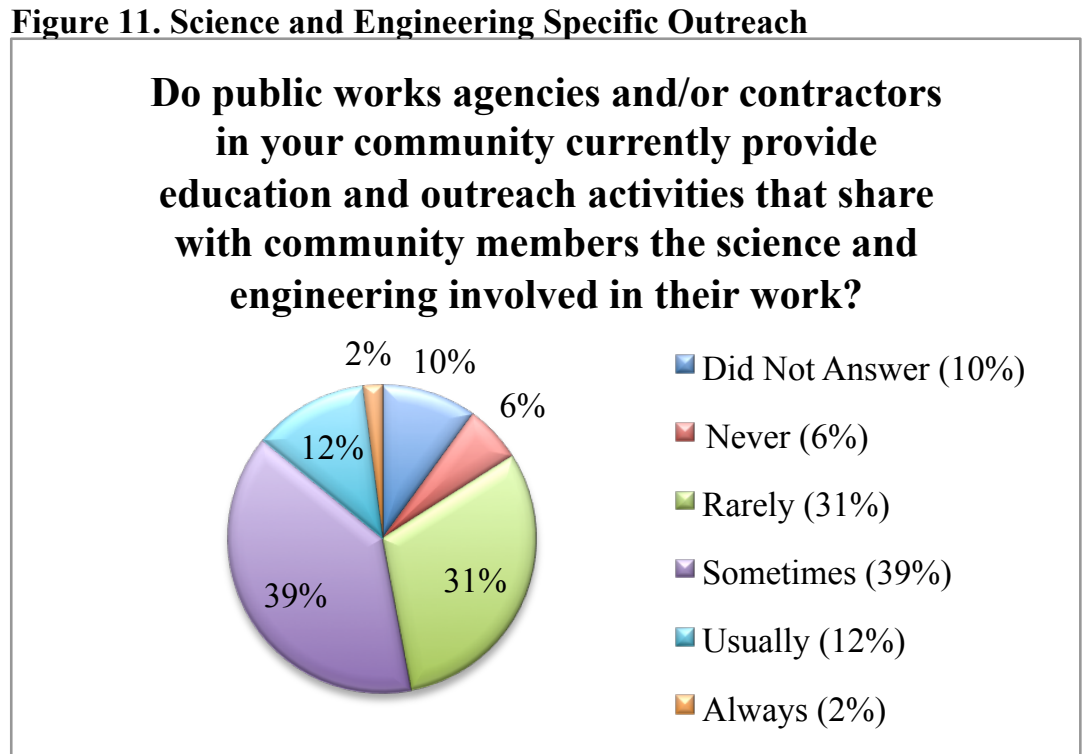

In order to increase the capacity of APWA agencies and members to pursue similar projects with science and engineering education components, the Golden Gate Bridge outdoor exhibit project was featured as an APWA Click, Listen, \& Learn professional development webinar. The twohour webinar, which was the most frequently requested professional development format by APWA members during a 2012 APWA Membership Survey, was presented on January 17, 2013. Presenters included a representative of the APWA and two professional evaluators with extensive experience in informal science and engineering education from David Heil and Associates, Inc., the summative evaluator on the Golden Gate Bridge outdoor exhibit project. A total of 67 sites participated in the course, which was designed to introduce APWA members to informal learning strategies, the benefits of public outreach and education activities, examples of sites currently providing science and engineering outreach, and practical project considerations, such as information regarding program evaluation and potential funding sources.

During the webinar, the participants were also asked to share what types of outreach activities their agency had previously utilized. The participants were provided the same set of choices used in the APWA Membership Survey, but with "Interpretive Exhibits and Displays" divided into 
two answers. Their responses were similar to the full membership, but the percentage of the responding sites that selected "Interpretive Exhibits" notably fell to $22 \%$ (See Figure 12).

Figure 12. APWA Public Education and Outreach Efforts of APWA Course Participants

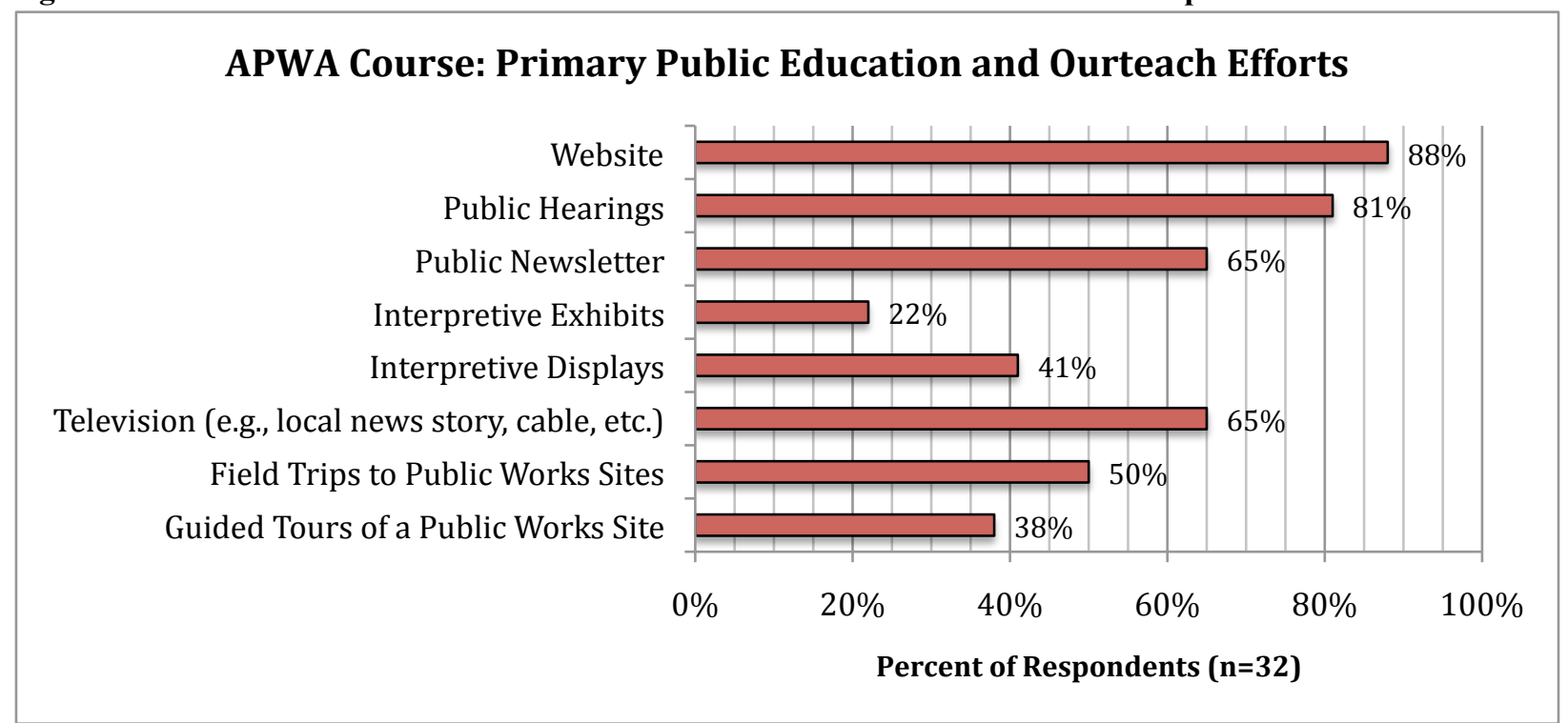

After the webinar, APWA requested feedback from the course participants, and a total of 26 participating sites responded. From this data, it was learned that $21 \%$ reported having no previous knowledge of the topic and $60 \%$ of the respondents were interested in expanding their current knowledge. After the program, nearly $90 \%$ of all of the respondents selected either "Agree" or "Strongly Agree" when indicating whether or not they felt more capable of conducting basic program evaluation assessments, identifying suitable collaborators to assemble a project team, identifying suitable funding sources, and identifying suitable education and outreach projects. $^{42}$

Figure 13. Additional APWA Course Participant Responses

\section{After viewing this program, I am now better able to:}

$\square$ Agree $\square$ Strongly Agree

Conduct basic evaluation assessments of a project's development, impact, and overal successes.

Inventory suitable collaborators and assemble the right team.

Identify potential sources of funding and support.

Identify suitable projects for education and outreach.

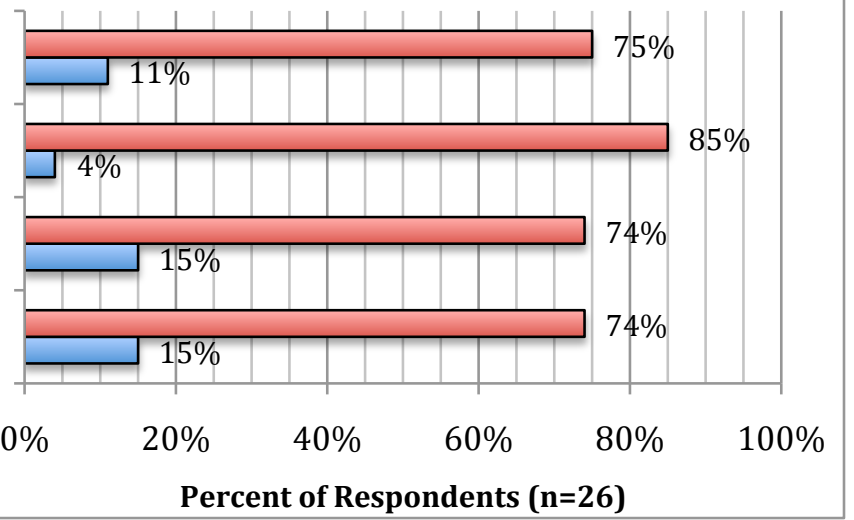




\section{Conclusion: Future Research Plans}

GGBHTD and its collaborative partners received funding to purse the development of a largescale project with broad, overarching goals. During the implementation of this project, GGBHTD and its collaborative partners created an outdoor exhibit that utilizes the site's access to the physical Golden Gate Bridge to specifically teach visitors about the science and engineering principles inherent in its design. The project also provided university students an opportunity to become aware of, and engaged, in STEM education via exhibit design; organized and hosted an international conference; and created an APWA webinar course to enhance the capacity of public works professionals to create similar site-based, STEM education resources in their own communities.

While exhibit components are still slowly being incorporated into the site and the summative evaluation has only recently begun, already the GGBHTD project has enriched public, university student, and professional audiences. As the summative evaluation continues, more research will be conducted to examine the exhibit's impact on visitors, including international visitors who comprise a large percentage of the site's daily attendance. There is also interest in investigating how the next generation science standard's emphasis on engineering will impact local San Francisco schools' utilization of the Golden Gate Bridge as a resource. And finally, as the project approaches its' final year, evaluators plan to survey and interview project partners to further explore the dynamics, challenges, and successes of the collaborative project model.

\section{References}

1. Mulligan, D. (2012). Project Overview. Retrieved December 4, 2012 from http://www.pwplconference.com/agenda_files/presentations-day1/1_Project_Overview-Mullligan.pdf.

2. Ainsworth, H., \& Eaton, S. (2010). Formal, non-formal and informal learning in the sciences, (pp 29-30) Onate Press.

3. Falk, J. \& Dierking L. (2002) Lessons Without Limit: How Free-Choice Learning is Transforming Education, (p. 27) AltaMira Press.

4. History Channel: Modern Marvels. Retrieved December 4, 2012 from http://www.history.com/shows/modernmarvels/episodes.

5. Science Channel: How It's Made. Retrieved December 4, 2012 from http://science.discovery.com/tvshows/how-its-made/season-1-episodes.htm.

6. Anagnos, T., Carroll, B., Weiss, S. \& Heil, D. R. (2013). Public Works for Public Learning: A Case Study, $120^{\text {th }}$ ASEE Annual Conference \& Exposition. Atlanta, GA.

7. Mulligan (2012).

8. Falk and Dierking, (2002). (p. 35).

9. Gardner, H. (1991). The Unschooled Mind: How Children Think \& How School Should Teach, (p. 12). BasicBooks.

10. Gardner, (pp. 244-46).

11. Crane. V. (1994). Informal Science Learning: What the Research Says About Television, Science Museums, and Community-Based Projects. An Introduction to Informal Science Learning and Research. (p. 3). Science Press.

12. Bell, P., Lewenstein, B., Shouse, A., \& Feder, M. (Edt.). Learning Science in Informal Environments: People, Places, and Pursuits (p. 11). The National Academies Press.

13. Ainsworth \& Easton, (2010), (p. 30).

14. Falk and Dierking, (2002), (p. 10).

15. Falk and Dierking, (2002), (p. 40).

16. Bell et all. (2009). 
17. David Heil \& Associates, Inc. (2013) Site Observations.

18. Site Observations, (2013).

19. Site Observations, (2013).

20. Site Observations, (2013).

21. David Heil \& Associates, Inc. (2013) Golden Gate Bridge Visitor Survey Findings.

22. Golden Gate Bridge Visitor Survey Findings, (2013).

23. Golden Gate Bridge Visitor Survey Findings, (2013).

24. Garlock, M. (2012) The Pedagogical Value of Designing Exhibition. Retrieved December 6, 2012, from $\mathrm{http} / / / \mathrm{www} . p w p l c o n f e r e n c e . c o m / a g e n d a \_f i l e s / p r e s e n t a t i o n s-d a y 1 / 8$ _Design_and_Fabrication-Garlock.pdf.

25. Garlock, (2012).

26. Black, S. (2012) More Than a Model: The Golden Gate at 1:80 Scale. Retrieved March 15, 2013, from http://www.pwplconference.com/agenda_files/presentations-day1/9_Bridge_Model-Black.pdf

27. Garlock, (2012).

28. Garlock, (2012).

29. Garlock, (2012).

30. Public Works for Public Learning: Conference Agenda. Retrieved December 6, 2012 form http://www.pwplconference.com/agenda.php.

31. Bowe, J. Bridge Climb: Exploring and Experiencing the Sydney Harbour Bridge. Retrieved December 6, 2012 from http://www.pwplconference.com/agenda_files/presentations-day1/5_BridgeClimb-Bowe.pdf.

32. Mulligan, (2012).

33. Public Works for Public Learning: Conference Agenda

34. David Heil \& Associates, Inc. (2012) Public Works for Public Learning: Post-Conference Survey Findings.

35. Public Works for Public Learning: Post-Conference Survey Findings, (2012).

36. Public Works for Public Learning: Post-Conference Survey Findings, (2012).

37. Public Works for Public Learning: Post-Conference Survey Findings, (2012).

38. David Heil \& Associates, Inc. (2012) APWA Membership Survey Findings.

39. APWA Membership Survey Findings (2012).

40. APWA Membership Survey Findings (2012).

41. APWA Click, Listen \& Learn: Leveraging Public Works for Outreach Education. Heil, David, Shannon Weiss, and Larry Lux. Retrieved April 2, 2013 from https://apwa.adobeconnect.com/_a825035819/p62qz3dct8t/?launcher=false\&fcsContent=true\&pbMode=normal

42. American Public Works Association. CCL - Leveraging Public Works for Outreach and Education: Feedback Findings, 2013. 